Personalidade Acadêmica Homenageada:

Florisbal de Souza Del'Olmo (Professor Convidado - UNICURITIBA)

\title{
O NOVO PERFIL DA ADVOCACIA EMPRESARIAL: COMO A TECNOLOGIA DE BLOCKCHAIN IRÁ COMPLEMENTAR DE MANEIRA POSITIVA O COMPLIANCE
}

\section{OR NOVO PROFILE ADVOCACIA EMPRESARIAL: AS A \\ BLOCKCHAIN TECHNOLOGY WILL BE COMPLEMENTARY OF POSITIVE MANEIRA OR COMPLIANCE}

LUIZ EDUARDO DA CUNHA DARIN

Mestrando em Direito pelo Centro Universitário Curitiba (UNICURITIBA). Bacharel em Direito pelo Centro Universitário Curitiba (UNICURITIBA). Professor da Dispute Boards Academy (DBA). Professor do Grupo de Competição em Negociação e Mediação do Centro Universitário Curitiba (UNICURITIBA). Membro do Programa de Negociação Internacional da Escola de Direito de Harvard (PON). Membro do Grupo de Direito Empresarial Societário do Mestrado do Centro Universitário Curitiba (UNICURITIBA). Membro do Grupo de Direito, Epistemologia e Sustentabilidade do Mestrado do Centro Universitário Curitiba (UNICURITIBA). Possui capacitação em arbitragem internacional pela Faculdade Getúlio Vargas (FGV). Professor convidado em diversos cursos de graduação, pós-graduação e eventos, nacionais e internacionais.

\section{MARIANA BAPTISTA DE ASSUMPÇÃO}

Aluna do curso de Direito do Centro Universitário Curitiba (UNICURITIBA). Membro do grupo de competição de Negociação e Mediação em Disputas Empresariais do Núcleo de Pesquisa e Extensão Acadêmica (NPEA) do Centro Universitário Curitiba (UNICURITIBA). 


\section{Personalidade Acadêmica Homenageada:}

Florisbal de Souza Del'Olmo (Professor Convidado - UNICURITIBA)

\section{RESUMO}

No presente trabalho, através de uma metodologia bibliográfica investigativa, buscase apresentar como o novo perfil da advocacia contemporânea no Brasil, tem se moldado. É utilizado para isso, o marco teórico da aprovação da "Lei Anticorrupção" nesta "nova fase" do Direito brasileiro e como seus desdobramentos se compuseram para termos o que hoje chamamos de Instituto de Compliance. Em um segundo momento, é apresentada uma nova teoria, denominada de Blockchain, que através das considerações feitas durante o trabalho, é capaz de superar as expectativas que o Instituto de Compliance possui, eliminando o Fator Humano do instituto e chegando em uma segurança jurídica de 100\%. Conclui-se então que o novo papel da advocacia no Brasil, tem feito um bom trabalho se apropriando de institutos internacionalmente famosos por seus resultados positivos, porém ainda é embrionário, necessitando de mais estudo e interesse. Desta forma teremos um advogado não tão conceitualmente raso, o que possibilitará um referencial positivo ao Profissional de Advocacia Brasileiro e uma maior segurança jurídica na realização de negócios.

PALAVRAS-CHAVE: Blockchain; Compliance; Direito Empresarial; Advocacia; Tecnologia.

\section{ABSTRACT}

The present work, comes through a bibliographic and research methode to present the new contour of brazilian advocacy and how it has been shaped at nowadays cenario. It's our departure point the theoretical landmark of the "Anti- corruption law" at this new fase of brazilian law as the unfoldings that lead us to the Compliance Institute. Secondly it's portrayed the new Blockchain theory, and the considerations made include the expectation of overcoming the Compliance Methode as the human factor is eliminated and reaches for the $100 \%$ juridical security. Thus, one may conclude that the new rol of advocacy in Brazil has duly appropriated international institutes although at a start-up phase, needing further development and study. This 


\section{Personalidade Acadêmica Homenageada:}

Florisbal de Souza Del'Olmo (Professor Convidado - UNICURITIBA)

way we belive that it will lead the laywers to a new perspective and enhancement, creating a new referencial and further juridical security at business.

KEYWORDS: Blockchain; Compliance; Business Law, Advocacy, Tecnology.

\section{INTRODUÇÃO}

Inegável é o fato de que o Direito por ser uma Ciência Humana, está muito longe de ser exato, ao mesmo tempo em que está sob uma constante mudança, ou seja, conforme a sociedade humana evoluí, os pensamentos acerca de tal ciência jurídica, buscam acompanha-la, sempre respaldando-se na justificativa do melhor bem estar social, ou seja, da uniformidade utilitarista ampliada do bem-estar social.

Por décadas a discussão sobre a Teoria Geral do Direito, obteve seu debate centrado sobre duas grandes Teorias, por um lado pensamentos que visavam a positivação excessiva através de conceitos de regras e generalidade e por outros pensamentos que visavam a eliminação da discricionariedade no cenário jurídico e a limitação do poder á magistrados por exemplo (SAAVEDRA 2006).

Estamos falando das Teorias Positivas e Pós-positivistas, que dentre seus embates históricos tivemos como propulsores, pensadores e filósofos como H.L.Hart e A. Dworkin (BOBBIO 1995). Porém com a chegada do novo milênio e a forte globalização que os meios de comunicação, como a própria internet, propuseram ao Direito, as discussões sobre qual seria a melhor forma de se aplicar a regra, como se daria o sento coercitivo da mesma e como ficariam pensamentos arbitrais do poder discricionário do magistrado, acabam ficando de lado, dando luz a uma nova fase do Direito.

Esta nova fase é a que se contextualiza o presente trabalho, além de nova é extremamente atual e principalmente no cenário brasileiro. Cansados de discussões sobre seguridade jurídica ou até mesmo da grande inflação vivida pelos tribunais brasileiros, o Direito no brasil, começa em 2015 com a aprovação de um novo Código de Processo Civil, um novo marco teórico, uma nova fase, onde os Tribunais 


\section{Personalidade Acadêmica Homenageada:}

Florisbal de Souza Del'Olmo (Professor Convidado - UNICURITIBA)

agora desprovidos de uma porta única historicamente chamada de litigiosa, de desdobram em teorias internacionais para oferecem a sociedade multiportas para a resoluções do litigio (SADEK 2016).

Contudo, do mesmo modo que a oxigenação do pensamento jurídico brasileiro, através de teorias como a do Tribunal Multiportas e dos novos Meios Alternativos de Resolução de conflitos, diversas leis federais foram aprovadas, como a "Lei Anticorrupção" e Leis que positivaram no ordenamento jurídico procedimentos de Mediação e Arbitragem.

Neste contexto, na matemática logica de se adaptar a mudanças visando ganho de mercado e avanço acadêmico e cultural, a advocacia tem sido alterada constantemente. Advogados, doutrinados em academias sob a polarização do conflito, se veem em uma realidade onde é necessária a superação de tal paradigma, e começam a também beber de fontes internacionais.

Eis aqui uma grande problemática, quais são os reflexos do novo marco teórico no Direito Brasileiro para o perfil da Advocacia Empresarial Brasileira, como está têm se adaptado a um novo conceito de judiciário e a uma forte internacionalização procedimental do Direito?

É objetivo deste trabalho, debater está problemática, tomando como exemplo, atualmente uma das práticas mais comuns na advocacia brasileira, o Compliance. A partir de que momento este instituto se popularizou no Brasil, como ocorre sua interiorização no cenário empresarial nacional e se não estaria ele sendo aplicado de maneira incorreta.

Neste intuito, bebendo nas fontes internacionais, também se traz ao presente trabalho uma nova teoria, denominada de Blockchain, que através de uma metodologia bibliográfica nos permite analisar se elementos internacionais, no caso em tela o Compliance, estão sendo explorados na sua totalidade, de forma positiva, pelo novo perfil da advocacia empresarial brasileira, que se molda a nova realidade jurídica do país. 


\section{Personalidade Acadêmica Homenageada:}

Florisbal de Souza Del'Olmo (Professor Convidado - UNICURITIBA)

\section{O NOVO CENÁRIO JURÍDICO BRASILEIRO}

Não é segredo para ninguém os problemas que o sistema judiciário brasileiro vem enfrentando ao longo dos últimos anos. Com o sucesso da aplicação do Código de Defesa do Consumidor, assim como com a privatização e expansão de serviços públicos e a democratização dos serviços bancários, cada vez mais o sistema judiciário é procurado como forma de resolver lides, o que por obvio resulta em um grande crescimento no número de processos (BARBADO 2004).

Com o aumento da demanda processual no Brasil, o sistema judiciário se mostrou cada vez mais falho, desencadeando assim uma insegurança jurídica. Visando colocar fim nesta insegurança, o legislador brasileiro sabiamente começa então a procurar soluções em experiências estrangeiras bem-sucedidas

Não obstante uma séria de bem-sucedidas experiências estrangeiras, reconhece-se que o legislador brasileiro buscou inspiração na legislação argentina, que desde 1995 dá destaque à mediação, bem como se orientou pela ideia norteamericana de "Tribunal Multiportas" quando do estabelecimento das diretrizes nacionais para o tratamento dos meios consensuais de solução de conflitos no Poder Judiciário (BARBADO 2004).

\subsection{NOVOS INSTITUTOS EMERGENTES NA "NOVA FASE" DO DIREITO BRASILEIRO.}

Atualmente frente ao imenso dinamismo social cada vez mais o Direito tem buscado novas formas de atender aos interesses de celeridade, praticidade e informatização que despontam no cenário internacional.

Com este intuito inúmeros institutos reconhecidos em países da Europa e nos Estados Unidos tem ganhado cada vez mais destaque entre os escritórios de advocacia brasileira, a considerar mecanismos como due diligence em fases pré contratuais, cláusulas escalonadas, contratos de EPC, dentre outros.

Mecanismos como a mediação digital, que busca maior acessibilidade, uma vez que supera a barreira física no alcance da justiça, e informatiza o procedimento 


\section{Personalidade Acadêmica Homenageada:}

\section{Florisbal de Souza Del'Olmo (Professor Convidado - UNICURITIBA)}

de mediação de forma a torna-lo mais rápido e fácil tem ganhado destaque, bem como o inovador sistema de escrow account que serviria de garantia em operações de alto risco, sendo administrada por um terceiro e evitando surpresas financeiras inesperadas em casos de insucesso, também objetivando maior rapidez e segurança, fatores fundamentais em se tratando de relações comerciais e direito empresarial moderno.( VIERA 2017)

O direito, portanto, tem se apropriado de forma eficaz e muito benéfica de institutos que garantem clareza e celeridade nos procedimentos jurídicos, buscando otimizar contratos, relações negociais entre parceiros e interessados e o próprio cotidiano de seus tutelados.

Nesse mesmo viés trazemos neste artigo dois institutos internacionais que tem cada dia mais se tornado presentes nas operações do direito contemporâneo, dentre eles o compliance o blockchain, modernas ferramentas de transparência e garantia de maior segurança e celeridade, são temas que se tornaram vitais para o conhecimento jurídico do advogado contemporâneo.

\section{COMPLIANCE}

Diferente do que muitos podem pensar, aspectos jurídicos culturais que fundamentam práticas jurídicas como Compliance não são tão novos entre nós. Em 1998 com a publicação da Resolução número 2.554 do Banco Central do Brasil, ocorreu uma forte incorporação de regras presentes em ordenamentos Europeus (Comitê da Basiléia para a Supervisão Bancária) e Norte-Americanos (Comitê de Segurança Financeira) ao ordenamento jurídico brasileiro (MARTINEZ 2016).

O que não havia até então ocorrido era uma dosagem baseada em "pesos e contrapesos" por parte do legislador brasileiro, o que com o advento da Lei número 12.846 de 2013, finalmente ocorreu e por obvio chamou a atenção do empresário brasileiro.

A lei demonstrou por parte do legislador, uma simetria entre a dosagem de seus artigos em face do Art.59 do Código Penal, desta maneira a mesma prevê uma 


\section{Personalidade Acadêmica Homenageada:}

Florisbal de Souza Del'Olmo (Professor Convidado - UNICURITIBA)

espécie de análise de conduta social e da "personalidade" da empresa. Em outras palavras, quanto mais ética e em conformidade às leis e regulamentos estiver de fato a empresa, menor poderá ser a sanção a ela imposta (MARTINEZ 2016).

\subsection{O SURGIMENTO DO COMPLIANCE NA ADVOCACIA EMPRESARIAL BRASILEIRA}

Em face do novo contexto trazido pela Lei "Anticorrupção" e no anseio de atender uma nova vontade que começava a pulsar no empresário brasileiro, visando ampliação da proteção do seu negócio e a minimização dos riscos do mesmo, a advocacia brasileira foi buscar em outros ordenamentos jurídicos uma possível solução para a superação do novo paradigma (FREIRE 2014).

Neste contexto ao analisar o cenário histórico do Direito Comparado NorteAmericano, foi possível constatar que desde 1913 o Board of Governors of the Federal Reserve ${ }^{1}$ visava instituir elementos jurídicos que possuíam fundamentos semelhantes ao compliance, o que somente após a quebra da bolsa de Nova York em 1929 e a criação de políticas intervencionistas como o "New Deal" e a Securities and Exchange Comission foi possível de acontecer (FREIRE 2014).

Ciente dos dados supracitados os advogados empresariais brasileiros, através de pesquisas elaboradas por parte da Associação Brasileira de Bancos Internacionais $(\mathrm{ABBI})$, começaram a aplicar o Compliance dentro do Direito Empresarial Brasileiro, o que só aumentou desde então. No ano de 2015, cerca de um ano após da efetivação do Complice no Brasil, $3 \%$ das empresas brasileiras já eram adeptas (ICTS 2015).

\subsection{O QUE É COMPLICE?}

\footnotetext{
${ }^{1}$ Banco Central Americano

2 Durante o governo democrata de Franklin Rooselver, através de conceitos Keynesianos, este determinou que o Estado deveria intervir na Economia em favor do capitalismo.
} 


\section{Personalidade Acadêmica Homenageada:}

\section{Florisbal de Souza Del'Olmo (Professor Convidado - UNICURITIBA)}

Compliance é um conjunto de medidas internas que permitem prevenir ou minimizar os riscos de violação às leis decorrentes de atividade praticada por um agente econômico e de qualquer um de seus sócios ou colaboradores (CADE 2016).

É através de programas de Compliance que acontece uma forte integração de áreas diversas, ou seja, uma somatória de fatores e ampliações de competências, com um objetivo único de se evitar fraudes ou possíveis desandei-os.

Os agentes corporativos envoltos neste tipo de procedimento possuem um compromisso não somente com o cumprimento da legislação, mas também com uma alteração cultural intelectual própria em face do seu papel frente a empresa.

É com base nesse contexto que se elogia a prática de programas como Compliance, agregando á ele critérios como a ética empresarial no ambiente cooperativista e princípios subjetivos as relações empresárias como responsabilidade contratual ampla e boa-fé empresarial.

O Compliance também é uma das principais ferramentas para se alcançar os objetivos estratégicos de uma empresa. A sinergia presente com todas as normas da empresa, ditames de regulamentação e controles internos eficientes, representam maior qualidade na atividade empresarial (respeito às normas de qualidade), economia de recursos (evitando gastos com multas, punições e cobranças judicias) e fortalecimento da marca no mercado (ENDEAVOR 2016).

\subsubsection{Como se desenvolve o Programa de Compliance}

O debate em torno de como se deve criar uma área de Compliance é bastante amplo, assim como os conceitos que cercam esse tipo de programa. Como consequência imediata disto, a formatação de como se deve constituir tal área possui latente divergência na doutrina jurídica brasileira.

Alguns doutrinadores como Fernando Guimarães acreditam que para se implementar uma área de Compliance é necessário cerca de 13 passos fundamentais (fazer diagnósticos, analisar a estrutura organizacional da empresa, seu planejamento, seu código de conduta políticas essenciais, quais são suas atividades sensíveis, qual é o seu canal de denúncias, como é feito o treinamento 


\section{Personalidade Acadêmica Homenageada:}

\section{Florisbal de Souza Del'Olmo (Professor Convidado - UNICURITIBA)}

interno dos agentes que atuam na empresa, como é realizada a comunicação empresarial interna e externa, como ocorre o monitoramento das ações internas da empresa, como são investigadas possíveis violações e como é feito o acompanhamento dos atos da empresa em face da legislação) (GUIMARÃES 2017).

Já outros como Gerald Kenny acreditam que apenas com 4 passos (política de organização compreensível, treinamento consistente e de alto nível, uma equipe desempenhando um papel prático e um forte gerenciamento de todos os problemas) (KENNY 2018) seria possível implementar uma área de Compliance.

Obviamente os autores citados servem apenas como exemplos para se comprovar tal argumento, mas se fossemos mais afundo poderíamos trazer diversos pontos de vista sobre constituição destas áreas de Compliance.

\subsection{PONTOS NÃO POSITIVOS DO PROGRAMA DE COMPLIANCE PARA AS ORGANIZAÇÕES}

Como já trazido por este trabalho, as beneficies que acompanham a implementação do programa de Compliance são quase irrefutáveis, porém existe um fator nesta conta que pode não se encaixar.

Por mais que a doutrina seja divergente em face de como implementar as áreas de Compliance, um ponto apresenta-se unanimemente comum, seja qual for a forma escolhida para praticar tal programa, sempre será necessário um material humano para o realiza-lo.

Neste contexto eis uma pergunta muito importante, é possível se confiar $100 \%$ no material humano em face do trabalho exigido e necessário por um programa de Compliance?

Á luz de tal questionamento, devemos refletir sobre a seguinte afirmação, o Compliance não é uma finalidade em si mesma. É antes de tudo, um indispensável instrumento de gestão de risco, por meio do qual, em conjunto com outros, se mitigam os principais riscos de uma organização. Cada colaborador possui uma função para o efetivo sucesso de tal programa, possuindo assim um risco humano que por anos persegue a humanidade, a falha (SUSS 2017). 


\section{Personalidade Acadêmica Homenageada:}

\section{Florisbal de Souza Del'Olmo (Professor Convidado - UNICURITIBA)}

Como poderíamos resolver este tipo de problema, que aparentemente é pequeno e com poucas chances de acontecer, mas que a longo prazo pode se tornar grande? Como o empresário brasileiro pode obter $100 \%$ de confiabilidade com este tipo de programa?

Para responder a tais problemáticas devemos então anular os fatores de risco, descontruindo onde estes estão presentes e com base nisso procurar soluções. Na problemática supracitada observamos o fato humano interferindo em uma ciência quase perfeita.

A medida que retiramos este fator do contexto nos deparamos com a seguinte pergunta, quem irá realizar o controle de todos os amplos mecanismos presentes no programa de Compliance? Quem irá fiscalizar o cumprimento deles? Quem irá verificar as medidas empresárias internas em face da legislação?

É como resposta a estas perguntas e com o intuito de melhorar algo que já é comprovadamente bom que inserimos neste contexto a prática de blockchain.

\section{BLOCKCHAIN}

O sistema também denominado de "cadeia de dados" surgido em 2008, adentra o cenário legal brasileiro agora como um complemento eficaz para o já conhecido, porém ainda recente Compliance, agregando técnicas de criptografia e o dinamismo da descentralização de fontes, a tecnologia promete revolucionar a forma como confiamos e transacionamos informações (RIBEIRO 2017).

O blockchain inicialmente idealizado como forma de validar informações, transações e registros de dados online e aplicado principalmente nos sistemas de moedas digitais como Bitcoin, Monero e Ethereum, foi transposto para os mecanismos de compliance com finalidade similar, assegurar a confiabilidade e inviolabilidade de informações, servindo até mesmo como um conjunto de regras que viabiliza o sucesso das operações empreendidas. 


\section{Personalidade Acadêmica Homenageada:}

\section{Florisbal de Souza Del'Olmo (Professor Convidado - UNICURITIBA)}

Cabe, portanto a nos operadores do direito compreendermos quais as vantagens e desvantagens deste mecanismo frente aqueles que já possuímos e buscar entender como aplica-lo na realidade atual.

\subsection{O QUE É BLOCKCHAIN}

Para melhor compreendermos o grande interesse pelo mecanismo primeiro cabe a nós uma análise tanto quanto minuciosa a respeito do próprio funcionamento pratico deste que apesar de apresentar detalhes técnicos em um panorama geral concretiza conceitos simples.

A tecnologia que deu uma nova perspectiva a três instrumentos já utilizados, a internet, a criptografia privada e um protocolo de governança, representou uma enorme inovação na segurança de informações, eliminando a necessidade de um terceiro servidor e apresentando maior celeridade e complexidade em suas etapas de inviolabilidade.

Em seu funcionamento basicamente as informações, ou transações nos casos das moedas digitais, são armazenadas pelo sistema em blocos de informações, sendo cada bloco distinto dos demais e apresentando uma assinatura única, denominada "hash", uma garantia criptográfica de que suas informações se encontram intactas. (MOUGAYAR 2016)

Cada "hash" não somente assegura a qualidade das informações bem como sua sequência lógica para com as demais que foram realizadas em sequência, uma vez que cada bloco novo carrega não apenas a sua "hash" como aquela do bloco anterior, mantendo o sistema organizado em cadeia, e, portanto, dando nome ao mecanismo blockchain.

Ademais cada uma das transações realizadas é mantida registrada em uma espécie de "livro razão digital", denominado ledger, que serve como registro das operações realizadas e disponível de forma numerada para aqueles que fazem uso do sistema, garantindo um controle ainda maior. (TAPSCOTT 2017)

A característica descentralizada da rede, que se estabelece em nós para a criação de novas hash, possibilita uma incrível expansão do mecanismo e um 


\section{Personalidade Acadêmica Homenageada:}

Florisbal de Souza Del'Olmo (Professor Convidado - UNICURITIBA)

grande dinamismo ao eliminar a presença de um terceiro servidor, e possibilitando que diversos usuários atualizem os dados e criem novas cadeias conforme o façam, provendo celeridade essencial em se tratando de moedas digitais e mercados de ações, ambos setores que hoje em dia fazem uso do mecanismo. (COINDESK 2017)

O mecanismo garante atualmente a segurança das informações não apenas de moedas, mas também de contratos, ações e vendas de imóveis, uma vez que sistema complexo de atrelamento de dados sucessivo torna as chances de violação exponencialmente menores, evitando fraudes e ataques.

\subsection{COMO O BLOCKCHAIN PODE COMPLEMENTAR DE MANEIRA POSITIVA O PROGRAMA DE COMPLIANCE}

Em busca de melhoramentos de um sistema de transparência e controle interno como o proposto pelo compliance devemos primeiramente nos questionar quais os problemas que o tornam falho e qual a melhor sistemática para supera-los, e assim como apontado acima, a maior barreira para uma concretização perfeita da idealização do método infelizmente perpassa pela falibilidade humana.

Assim como já citado pelo filosofo francês: "Tolerância é a consequência necessária da percepção que somos pessoas falíveis: errar é humano, e estamos o tempo todo cometendo erros" (VOLTAIRE,1763), portanto quando nos deparamos frente ao elemento humano na aplicação de qualquer método, indistintamente nos deparamos com a possibilidade deste falhar, uma vez que é de nossa própria natureza a imprevisibilidade e a imperfeição.

A superação da problemática que se instaura então se daria de forma quase que necessária pela substituição do elemento humano por outro em tese infalível, este no caso mecânico, automatizado, digital, e é exatamente por meio dessa realização que percebemos o grande potencial do mecanismo de blockchain.

Um sistema autônomo de garantia da seguridade de informações, que depende muito pouco da intervenção humana na criação de suas cadeias quase invioláveis de dados e que é capaz de se auto gerenciar, surge como uma 


\section{Personalidade Acadêmica Homenageada:}

Florisbal de Souza Del'Olmo (Professor Convidado - UNICURITIBA)

alternativa não apenas viável como também muito útil para a garantia da probidade nas relações e transações não apenas comerciais assim como imobiliárias e contratuais.

\subsection{COMO CONCILIAR O BLOCKCHAIN AO COMPLIANCE}

Considerando-se a grande expansão da ferramenta do blockchain, atualmente é viável vislumbrarmos o mesmo como uma forma de aperfeiçoarmos métodos já consolidados como o compliance garantindo o melhor uso de ambos sistemas de transparência e alta inviolabilidade.

O sistema inovador que traz a luz essa possibilidade é o denominado smart contratct, uma nova visão dos contratos não regidos apenas pelo Direito positivado que conhecemos, mas também por mecanismos de previsibilidade e auto execução, que garantem um maior sucesso nas operações contratuais, e maiores garantias quanto as condutas adotas pelos contratantes. (FLYNT, 2016)

A ideia principal surge em uma automatização do gerenciamento das relações negociais, uma vez que esses contratos inteligentes e auto gerenciáveis seriam baseados em pré-requisitos e condições, que validariam as ações realizadas e garantiriam o controle de desvios, unindo ambas transparência e tecnologia.

Em termos práticos em um caso de atraso no pagamento de uma parcela de pagamento por exemplo, o contrato automaticamente computaria os valores devidos em multas e juros, podendo vir a bloquear possíveis ações atreladas ao adimplemento da obrigação não cumprida, sem a necessidade de pouca ou até mesmo nenhuma ação das partes.

O potencial de expansão da interação entre esses dois instrumentos é vasto e empresas reconhecidas tem adotado métodos semelhantes, como Itaú, Bradesco, JP Morgan, Deloitte, dentre outros, demonstrando que além de um mecanismo em desenvolvimento este é vislumbrado para um futuro próximo em empreendimentos de alta complexidade. 
Personalidade Acadêmica Homenageada:

Florisbal de Souza Del'Olmo (Professor Convidado - UNICURITIBA)

\section{CONCLUSÃO}

Diante do objetivo inicial proposto por este trabalho, podemos concluir que o novo papel da advocacia brasileira, busca inspiração em institutos já consagrados de maneira positiva no cenário internacional, para se alinhar as novas metodologias do judiciário brasileiro.

Neste sentido, com a aprovação da "Lei Anticorrupção", o Advogado brasileiro não hesitou em interiorizar e adaptar o Instituto de Compliance para realidade brasileira. Com a justificativa de que isto beneficia a empresa e o empresário, o sucesso de tal Instituto foi quase que imediato, se tornando um dos mais utilizados atualmente no país.

E nesse intuito de otimizar cada vez mais a realidade do direito empresarial, surge quase que simultaneamente a adaptação do mecanismo financeiro de blockchain para a maior seguridade de dados, elemento fundamental em se tratando de confidencialidade e confiança.

É nosso apontamento neste trabalho o vasto universo que surge com a visão complementar de ambos os institutos, uma vez que ao serem utilizados de forma simultânea e interligada estes possuem grande potencial para a viabilização do compartilhamento de informações de forma transparente e segura, otimizando as relações contratuais e facilitando o próprio gerenciamento das relações préexistentes como exemplificado pelos smart contracts.

Cabe, portanto, ao advogado contemporâneo compreender as demandas do dinamismo social e se manter em constante atualização para desta forma vencer a característica estática própria do âmbito metodológico e fazer assim o melhor uso das novas tecnologias a favor não apenas de si, mas da sociedade como um todo.

\section{REFERÊNCIAS}

ALEIXO, G; RADU, R. Blockchain e o futuro da governança. Medium. 2015. Disponível em: <https://medium.com/@ITSriodejaneiro/blockchain-e-o-futuro-dagovernança-959265cc4d66>. Acesso em 17.10.2018 
Personalidade Acadêmica Homenageada:

Florisbal de Souza Del'Olmo (Professor Convidado - UNICURITIBA)

ARAÚJO, Camila Gualda. O compliance como instrumento de governança corporativa. FIESP-SP. Disponível em <http://www.fiesp.com.br/indices-pesquisase-publicacoes/artigo-compliance/>. Acesso em: 17.10.2018

BARBADO, Michelle Tonon. Reflexões sobre a institucionalização da mediação no direito positivo brasileiro. In: AZEVEDO, André Gomma de (coord). Estudos em Arbitragem, Mediação e Negociação. v. 3. Brasília: UNB, 2004. p. 211 a 215.).

BIANCOLINI, Adriano. Crise Institucional, Compliance e Blockchain: uma visão conciliatória do que está por vir. Jus.com.br. Publicado em 03/2018. Disponível em $<$ https://jus.com.br/artigos/64822/crise-institucional-compliance-e-blockchain-umavisao-conciliatoria-do-que-esta-por-vir>. Acesso em 20.10.2018.

BOBBIO, Norberto. O positivismo jurídico: lições de filosofia do direito. Tradução de Márcio Pugliesi, Edson Bini, Carlos E. Rodrigues, São Paulo: Ícone, 1995.

CERF, V; D, CLARK; LEINER, M; et al. Brief history of the internet. Internet Society. 2012. Disponível em: <http://www.internetsociety.org/internet/what-internet/historyinternet/brief-history-internet\#Origins>. Acesso em 21.10.18

DIEDRICH, Henning. Ethereum: Blockchains, Digital Assets, Smart Contracts, Descentralized Autonomous Organizations. Wildfire Publishing, Hatchette, UK, 2016.

DRESCHER, Daniel. Blockchain Básico: Uma introdução não técnica em 25 passos. São Paulo. Novatc Editora, 2018.

DWORKIN, Ronald. Levando os Direitos a Sério. (Trad.) Nelson Boeira. São Paulo: Martins Fontes, 2002.

DWORKIN, Ronald. Uma questão de princípio. Tradução de Luís Carlos Borges. 2 ed. São Paulo: Martins Fontes, 2005. Título original: A matter of principle.

FLYNT, Oscar. Smart Contracts: How to Use Blockchain Smart Contracts for Cryptocurrency Exchange. Createspace Independent Publishing Plataform, 2016.

GERARD, David. Attack of the 50 Foot Blockchain: Bitcoin, Blockchain, Ethereum \& Smart Contracts. Amazon Digital Services, 2017.

HART, Herbert L. A. O conceito de direito. Tradução de A. Ribeiro Mendes, Lisboa:Fundação Calouste Gulbenkian, 1986.

The Concept of Law, $2^{\text {a }}$ ed. Oxford, Oxford University, 1994.

LEE, J; LONG, A; STEINER, J; et al. Blockchain technology and legal implications of 'crypto 2.0'. BNA's banking report, n.104. 2015. Disponível em: 
Personalidade Acadêmica Homenageada:

Florisbal de Souza Del'Olmo (Professor Convidado - UNICURITIBA)

$<$ www.gibsondunn.com/publications/Documents/Lee-Long-Blockchain-TechnologyBNA-Banking-03.31.2015.pdf>. Acesso em 22.10.18

MOUGAYAR, William. Blockchain Para Negócios - Promessa, Prática e Aplicação da Nova Tecnologia da Internet. Rio de Janeiro. Alta Books, 2017.

NAKAMOTO, Satoshi. Bitcoin: a Peer-to-Peer Electronic Cash System. Publicado em outubro de 2008. Bitcoin.org. Disponível em < https://bitcoin.org/bitcoin.pdf>. Acesso em 18.10.2018.

OSTERWALDER, A; PIGNEUR. Y. Business Model Generation. Hoboken, EUA: John Wiley and Sons, ed. 1. 2010. Acesso em 19.10.2018

PRICE, Miles. Blockchain: The Complete Guide to Understanding Blockchain Technology. Paperback, 2017.

SAAVEDRA, Giovani Agostini. Jurisdição e democracia: uma análise a partir das teorias de Jürgen Habermas, Robert Alexy, Ronald Dworkin e Niklas Luhmann. Porto $\begin{array}{llll}\text { Alegre: } & \text { Livraria } & & \end{array}$

SADEK, Maria Tereza Aina. Poder Judiciário: perspectivas de reforma. Opinião Pública, Campinas, v. 10, n. 1, p. 01 a 62, Maio de 2004. Disponível em $<$ http://www.scielo.br/scielo.php?script=sci_arttext\&pid=S0104$62762004000100002 \&$ Ing=en\&nrm=iso >. Acesso em 15.10.2018.

SCHWAB, Klaus. A Quarta Revolução Industrial. 1' edição. São Paulo: Edipro,2016.

SCOTT, Tony. Blockchain: Blueprint to Dissecting The Hidden Economy! - Smart Contracts, Bitcoin, and Financial Technology (English Edition). Kindle, 2016.

TAPSCOTT, Don. Blockchain Revolution. Vários tradutores. 1르 edição. São Paulo: Senai-SP, 2016 